\title{
MARTÍ MARTÍ, JOAQUIM (2008), LA DEFENSA FRENTE A LA CONTAMINACIÓN ACÚSTICA Y OTRAS INMISIONES (BARCELONA, BOSCH) 151 PP.
}

Los problemas jurídicos son eminentemente prácticos. Esto, que es una verdad palmaria, muchas veces es olvidado por los tratadistas que, en más de una ocasión, nos concentramos en problemas de índole profundamente teórico y con poca aplicabilidad directa en el foro. Es en este contexto que un libro monográfico sobre las inmisiones sonoras y vibratorias parece sumamente adecuado y necesario.

En efecto, en los últimos veinte años, la jurisprudencia y doctrina españolas han incorporado la teoría de las inmisiones para combatir diferentes casos en que el uso de lo propio daña lo ajeno, incluyendo, por supuesto, las inmisiones acústicas.

Aunque la literatura y jurisprudencia al respecto son amplias ${ }^{1}$, faltaba una guía de orden práctico $\mathrm{y}$, nos atreveríamos a decir, casi casuístico, que permitiese al abogado del foro aproximarse al problema de una manera amena.

El trabajo del abogado Joaquim Martí i Martí relativo a contaminación acústica, nos parece una buena guía al respecto y una mane-

\footnotetext{
* Traducción título:

1 Solo en el medio español, y sin ánimo de ser exhaustivos, podemos mencionar: DíAz ROMERO, María del Rosario (2003): "La acción negatoria frente a las inmisiones en el derecho de propiedad" in Estudios Jurídicos en Homenaje al Profesor Luis Diez Picazo (Madrid, Thomson) t. III p. 36993721; EGEA, Joan (1994): "Acción Negatoria, inmisiones y defensa de la propiedad" (Madrid, Marcial Pons), 209 pp.; García SÁnchez, Justo (1999): Teoría de la Immissio (Oviedo, Universidad de Oviedo) 215 pp. Jiménez SAlcedo, María Carmen (2000): "El Régimen Jurídico de las Relaciones de Vecindad en Derecho Romano" (Madrid, Cajasur), 280 pp.; LÁZARO GUILlamón, Carmen (2007): "La Acción Negatoria" (Valencia, Tirant lo Blanch) 236 pp.; LLÁCER MATACÁs, María Rosa (2002): "Régimen Legal de las Servidumbres y la Vecindad en el derecho Civil Catalán" in AA. VV. "Tratado de Servidumbres" (Navarra, Aranzadi) 4233 pp.
}

ra sencilla de entrar en el complejo mundo de las inmisiones.

El supuesto básico es simple. El dueño de la planta baja de un inmueble abre un bar con todas las autorizaciones administrativas pertinentes. Sin embargo, el uso comercial que hace del mismo, genera graves inconvenientes a los demás habitantes del edificio, especialmente por los molestos ruidos que se producen. Las inmisiones acústicas que emite el bar y que soportan los vecinos, constituyen una proyección de las consecuencias de lo obrado en lo propio en los bienes ajenos de tal naturaleza, que hacen molesto o difícil el uso habitual de los vecinos de sus propios inmuebles, al menos para fines habitacionales, toda vez que se les impide dormir.

El supuesto es muy similar al recordado caso de la taberna de quesos del Derecho romano $^{2}$, en que el habitante de un piso inferior expele humos a los pisos superiores producto de su actividad industrial. La respuesta en ambos casos es la necesidad de cesar en tales actividades, toda vez que no es lícito realizar actos en lo propio que afecten lo ajeno, hasta el punto de impedir su uso normal. Como se señala en el Digesto 3 "que cada uno haga en lo suyo como le plazca, siempre que no inmita en lo ajeno".

Bajo esta premisa, que no es más que una aplicación del principio general de "no dañar a otro" 4 , es que se desarrolla la doctrina de las inmisiones, dentro de la cual se incardina esta obra.

El libro comienza con una"fuerte crítica a la legislación estatal administrativa española sobre ruidos (Ley 37/2003 del ruido, pp. 15 y ss.). El autor muestra las diversas incongruencias prácticas de esta legislación, especialmente

\footnotetext{
${ }^{2}$ D. $8,5,8,5$.

3 in suo enim alii hactenus facere licet, quatenus nibil in alienum immitta

${ }^{4}$ D. 1,1,10, donde Ulpiano nos da el famoso alterum non laedere como un precepto del Derecho
} 
Recensiones

en la zonificación que establece. La normativa otorga a distintas zonas diferentes niveles de protección por motivos no siempre justificados. El caso más llamativo es aquel de las zonas de protección por motivos turísticos. Parece poco acertado que se proteja más al viajero que viene un par de días de vacaciones, que al ciudadano que debe soportar molestos ruidos todo el año.

El autor recalca, además, lo poco prácticos y de difícil implementación que resultan los mapas acústicos que la Ley establece.

En cuanto a los valores señalados como aceptables para emisiones acústicas, el autor muestra la discordancia de la Ley con los cánones establecidos como máximos por la Organización Mundial de la Salud, siendo la legislación estatal excesivamente permisiva.

A juicio del autor, la Ley no contempla un régimen sancionatorio suficiente ni medidas encaminadas al remedio de la contaminación acústica. La mayor parte de las disposiciones estarían orientadas a la prevención, lo cual deja en un estado de indefensión a quienes ya son víctimas de la contaminación acústica.

Vale la pena mencionar el régimen de servidumbres acústicas contemplado por la legislación estatal. Al respecto, se establece la creación de zonas afectas a servidumbre acústica en torno a las infraestructuras de transporte viario, ferroviario, aéreo, portuario o de otros equipamientos públicos. En efecto, dichas servidumbres tienen sentido puesto que las inmisiones, sean directas (hacer en lo ajeno) o indirectas (hacer en lo propio proyectando las consecuencias de los actos en lo ajeno) solo son permisibles cuando media una servidumbre. Incluso, puede decirse que las servidumbres prediales son derechos reales a inmitir desde el predio dominante al sirviente ${ }^{5}$.

Así, mediante una servidumbre de ruidos, se permite proyectar contaminación acústica desde la infraestructura de trasporte a los

5 Jimenez SALCEDO, María Carmen (2000), p. 24. Es por ello que el artículo 947 de nuestro Código Civil no admite acciones posesorias en contra de servidumbres legítimamente constituidas. predios afectados. Evidentemente, esta normativa debiera contemplar una indemnización por la constitución de dicha servidumbre, puesto que los predios sirvientes podrían llegar a perder buena parte de su valor por el hecho de encontrarse afectos a la misma. A pesar de las críticas que el autor vierte en contra de esta institución (pp. 21 y ss.), pensamos que algo de dicha normativa debiera ser tomado por nuestra propia legislación, especialmente considerando casos tan escandalosos como la construcción del Acceso Sur de Santiago, donde muchas viviendas quedaron a solo sesenta centímetros de una autovía de alta circulación, sin ser sus propietarios indemnizados de manera alguna.

Hecho, el autor pasa a examinar las diversas normativas autonómicas relativas a la contaminación acústica (pp. 51 y ss.). Posiblemente, la mejor construida es la catalana (Ley CA de Catalunya 16/2002 de 28 de junio, de protección contra la contaminación acústica), que se ve complementada por la antigua Ley 13/1990 de inmisiones, hoy parte del nuevo Código Civil de Catalunya. En efecto, a través de la combinación de ambas se obtiene un régimen de protección contra la contaminación acústica bastante completo. Tanto es así, que la ley sobre inmisiones ha sido aplicada en todo el Estado español, a pesar de su carácter autonómico, por su calidad intrínseca, y al considerársela parte de la legislación de España, en su conjunto.

Las demás legislaciones autonómicas presentan regímenes menos desarrollados, aunque son tratadas con un buen nivel de detalle por el autor. Tal vez una de las disposiciones autonómicas más llamativas sea aquella de Baleares, que expresamente regula como vicio redhibitorio la falta de insonorización de las viviendas (p. 86).

El plato fuerte del libro es el análisis de la jurisprudencia civil en materia de ruidos (pp. 89 y ss.). En efecto, la jurisprudencia española ha encontrado en la aplicación de la teoría de las inmisiones el mejor remedio contra la contaminación acústica.

$\mathrm{Al}$ respecto, comienza tratando el problema de la regulación de la contaminación 
acústica por decibelios. En efecto, un límite de emisión establecido por la normativa administrativa en una cantidad promedio de decibelios, no protege contra fuertes irrupciones sonoras ocasionales. Un ejemplo curioso que entrega el autor es el caso de una finca que recibía cada noche cuatro fuertes emisiones de sonido provenientes de un horno. Puesto que el resto de la noche el horno no emitía ruido alguno, el promedio estaba dentro de la normativa, aunque los habitantes de la finca eran despertados cada noche cuatro veces.

Lleva razón el autor al señalar que los criterios en decibelios son insuficientes para asegurar la protección de las personas contra la contaminación acústica. Afortunadamente, la jurisprudencia española no los considera como un factor decisorio para establecer la legalidad de las inmisiones. Si bien es cierto que al superarse los decibelios establecidos por la normativa administrativa, inmediatamente puede establecerse la ilegalidad de la inmisión, no por el hecho de estar dentro de los parámetros administrativos puede decirse que no se esté produciendo contaminación acústica.

En este sentido, la normativa administrativa mira la protección del orden público y las relaciones de los particulares con la administración (p. 93) y su incumplimiento conlleva un ilícito administrativo. La teoría de las inmisiones vela por el resguardo de la propiedad y los intereses privados de los particulares, por lo que el cumplimiento de la normativa administrativa no obsta a su aplicación. En definitiva, lo que no puede pretenderse es que, por el simple hecho de cumplir con la normativa administrativa, no se estén menoscabando los derechos de otros particulares que puedan verse afectados por las inmisiones.

Así, por mucho que una industria cumpla con las normativas relativas a ruidos, igualmente puede estar perturbando seriamente el uso que los vecinos hacen de sus inmuebles, así como su salud e intimidad. Los problemas entre particulares tienen un carácter civil, y no cabe excusarse en el sim- ple cumplimiento de las disposiciones administrativas. En este sentido, el autor demuestra que la jurisprudencia española actualmente no solo no absolutiza las reglamentaciones en decibelios, sino que tampoco se guía por criterios netamente administrativos para resolver materias civiles.

En cuanto a las indemnizaciones, el autor muestra como la mayor parte de las audiencias provinciales de Catalunya han estimado procedente la indemnización del daño moral causado por las inmisiones de ruido, mostrando, incluso, un cierto sesgo objetivo en su establecimiento. En efecto, la mayor parte de la jurisprudencia catalana le basta con la prueba de la inmisión y de su carácter molesto para proceder a la condena a indemnizar los daños morales que puedan haberse causado.

Finalizado este interesante capítulo, el autor pasa revista a la jurisprudencia penal en materia de contaminación acústica (pp. 115 y ss.). Al respecto, dicha jurisprudencia se ha enmarcado en el artículo 325 de Código Penal Español de 1995, que tipifica los delitos contra el medio ambiente. No obstante lo interesante de la reglamentación, excede nuestra perspectiva nacional, atendido especialmente la inexistencia de tales delitos en nuestro ordenamiento.

A continuación, el autor analiza la jurisprudencia de lo contencioso-administrativo (pp. 129 y ss.). Nos llama la atención la existencia de condenas a la administración por omitir actuar efectivamente para prevenir el ruido. Esto ha sido considerado como una omisión al deber de servicio del Estado y al principio de servicialidad consagrado en el artículo 103 de la Constitución española.

Finalmente, el autor se dedica a analizar otras inmisiones distintas a las acústicas, como son las de olores, vibraciones y fluidos (pp. 137 y ss.), las de humos y polvo (pp. 143 y ss.) o la contaminación lumínica (p. 149). Aunque el capítulo presenta cierto interés por su visión sinóptica, la verdad es que parece demasiado apresurado. La visión es demasiado sucinta para un tema que merece una atención más detallada. Después de todo, las inmisiones 
acústicas son solo un tipo de inmisiones y no se comprende por qué, luego de consagrar tanta atención a una clase de inmisiones, las demás son tratadas tan a la ligera.
Creemos que el libro constituye un aporte al foro y su lectura puede resultar de sumo interés para los abogados dedicados a temas ambientales.

Carlos Felipe Amunátegui Perellóo

${ }^{6}$ El doctor Carlos Felipe Amunátegui Perelló cursó sus estudios de pregrado en la Pontificia Universidad Católica de Chile y se doctoró en Derecho Patrimonial en la Universidad Pompeu Fabra bajo la dirección del Dr. Juan Miquel González. En 2005 se incorporó como profesor de Derecho Romano a la Facultad de Derecho de la Pontificia Unviersidad Católica de Chile. Actualmente es Secretario académico del Programa de Doctorado en Derecho de esta Facultad y Secretario de Redacción de la Revista Chilena de Derecho. Sus principales líneas de investigación son el capitalismo en Roma y su expansión imperial, como también la lógica estoica y la obra de Gayo.camunate@uc.cl.camunate@uc.cl 